\title{
Localization and regulation of pancreatic selenoprotein $\mathbf{P}$
}

\author{
Holger Steinbrenner ${ }^{1, *}$, Anna-Lena Hotze $e^{1,2, *,+}$, Bodo Speckmann ${ }^{1}$, Antonio Pinto ${ }^{1}$, \\ Helmut Sies $^{1,3,4}$, Matthias Schott ${ }^{2}$, Margret Ehlers ${ }^{2}$, Werner A Scherbaum ${ }^{2}$ \\ and Sven Schinner ${ }^{2}$ \\ ${ }^{1}$ Institute for Biochemistry and Molecular Biology I, Heinrich-Heine-University, Universitätsstrasse 1, \\ D-40225 Düsseldorf, Germany \\ ${ }^{2}$ Department of Endocrinology, Diabetes and Rheumatology, University Hospital Düsseldorf, Moorenstraße 5, \\ 40225 Düsseldorf, Germany \\ ${ }^{3}$ Leibniz-Institut für umweltmedizinische Forschung (IUF), Heinrich-Heine-University, Auf'm Hennekamp 50, \\ D-40225 Düsseldorf, Germany \\ ${ }^{4}$ College of Science, King Saud University, Riyadh, Saudi Arabia \\ *(H Steinbrenner and A-L Hotze contributed equally to this work) \\ ${ }^{\dagger}$ (This work is part of the MD thesis of A-L Hotze at the Heinrich-Heine-University)
}

Correspondence should be addressed to S Schinner Email

sven.schinner@uniduesseldorf.de

\begin{abstract}
Progressive loss of pancreatic $\beta$-cell mass is a crucial feature of type 2 diabetes mellitus. As $\beta$-cells express very low amounts of the antioxidant enzymes catalase and glutathione peroxidase (GPx), they appear to be particularly vulnerable to oxidative damage in the pathogenesis of diabetes. Here, we investigated the pancreatic expression pattern and regulation of selenoprotein $\mathrm{P}$ (Sepp1), which may serve as an additional antioxidant enzyme inside and outside of cells. Sepp1 was detected in rodent pancreas by immunofluorescence and real-time RT-PCR. Regulation of Sepp1 biosynthesis in INS-1 rat insulinoma cells was investigated by real-time RT-PCR, luciferase gene reporter assay, and immunoblotting. Sepp 1 and Gpx1 gene expressions in rat pancreas were 58 and $22 \%$ respectively of the liver values. Pancreatic Sepp 1 expression was restricted to the endocrine tissue, with Sepp 1 being present in the $\alpha$ - and $\beta$-cells of mouse islets. In INS-1 insulinoma cells, Sepp 1 expression was stimulated by the selenium compound sodium selenate and diminished in the presence of high glucose (16.7 vs $5 \mathrm{mM}$ ) concentrations. Sepp $1 \mathrm{mRNA}$ stability was also lowered at $16.7 \mathrm{mM}$ glucose. Moreover, Sepp1 mRNA levels were decreased in isolated murine islets cultured in highglucose (22 mM) medium compared with normal glucose ( $5 \cdot 5 \mathrm{mM}$ ) medium. Pancreatic Sepp1 expression was elevated upon treatment of mice with the $\beta$-cell toxin streptozotocin. This study shows that pancreatic islets express relatively high levels of Sepp 1 that may fulfill a function in antioxidant protection of $\beta$-cells. Downregulation of Sepp 1 expression by high glucose might thus contribute to glucotoxicity in $\beta$-cells.
\end{abstract}
Key Words
- pancreatic islet
- $\beta$-cell
diabetes
- selenium
- selenoprotein
oxidative stress

\section{Introduction}

Insulin resistance is a hallmark in the pathogenesis of type 2 diabetes mellitus (T2DM). Pancreatic $\beta$-cells have the capacity to compensate for insulin resistance by a reactive increase in insulin secretion over a long period.
However, chronic nutrient overload may eventually result in $\beta$-cell failure, characterized by an impaired insulin secretory capacity upon glucose stimulation and enhanced apoptosis (Donath et al. 2003, Kahn 2003, http://jme.endocrinology-journals.org DOI: 10.1530/JME-12-0105
(C) 2013 Society for Endocrinology Printed in Great Britain 
Schinner et al. 2005). Oxidative/nitrosative stress induced by reactive oxygen and nitrogen species (ROS/RNS) including superoxide, hydrogen peroxide $\left(\mathrm{H}_{2} \mathrm{O}_{2}\right)$, nitric oxide (NO), and peroxynitrite is increasingly recognized to contribute to $\beta$-cell dysfunction and destruction in T2DM. The majority of cellular ROS production derives from electron leakage in the mitochondrial respiratory chain and from membrane-bound $\mathrm{NAD}(\mathrm{P}) \mathrm{H}$ oxidases (Nox), producing superoxide that can subsequently dismutate to $\mathrm{H}_{2} \mathrm{O}_{2}$ (Drews et al. 2010). Hyperglycemia results in increased superoxide generation in rat islets in vitro and in vivo (Bindokas et al. 2003, Tang et al. 2007). Proinflammatory cytokines that are produced in the adipose tissue of insulin-resistant individuals (Hotamisligil et al. 1993, Donath et al. 2003) have been reported to enhance superoxide and $\mathrm{NO}$ levels in $\beta$-cells through stimulation of Nox and inducible NO synthase (iNOS; Darville \& Eizirik 1998, Morgan et al. 2007, Drews et al. 2010). The reaction of NO with superoxide generates peroxynitrite, a potent mediator of $\beta$-cell destruction (Lakey et al. 2001).

Oxidative stress due to imbalance of oxidants and antioxidants may result in damage of cellular macromolecules and cell death (Sies 1986). Interestingly, pancreatic islets are among the weakest endowed tissues in terms of their antioxidant defense status. Expression and activity of the $\mathrm{H}_{2} \mathrm{O}_{2}$-reducing enzymes catalase and glutathione peroxidase (GPx) are particularly low in islets, exhibiting around $5 \%$ of the values in liver. Superoxide dismutases (SOD) are moderately expressed in islets (Tiedge et al. 1997). On the other hand, $\beta$-cells express relatively high levels of peroxiredoxins, an additional enzymatic antioxidant system that is inducible by oxidative stress (Bast et al. 2002).

Selenoprotein P (Sepp1 (SEPP1)) is another protein with a putative antioxidant function, even though it is primarily known as plasma protein that supports peripheral tissues with the essential micronutrient selenium (Se; Burk \& Hill 2009, Steinbrenner \& Sies 2009). Two enzymatic activities have been demonstrated for Sepp1, a peroxynitrite reductase and a phospholipid hydroperoxide GPx (PH-GPx) activity (Arteel et al. 1998, Takebe et al. 2002). While hepatocytes produce and secrete the bulk of Sepp1 circulating in plasma, Sepp1 mRNA is present ubiquitously in most tissues (Burk \& Hill 2009). Knockdown of Sepp1 biosynthesis in astrocytes and in adipocytes has been shown to increase their sensitivity for oxidative damage (Steinbrenner et al. 2006, Zhang \& Chen 2011). Sepp1 mRNA has also been detected in the mouse pancreas (Lee et al. 2008), where it has been described to be enriched in $\beta$-cells compared with $\alpha$-cells of islets (Niwa et al. 1997).

Here, we provide evidence that expression of Sepp1 in pancreas is restricted to the islets of Langerhans. We investigated Sepp1 regulation by glucose in INS-1 rat insulinoma cells and in mice islets in vitro and by treatment of mice with the $\beta$-cell toxin streptozotocin (STZ) in vivo.

\section{Materials and methods}

\section{Reagents and antibodies}

Se compounds, glucose, STZ, and actinomycin D were from Sigma. Reagents for SDS-PAGE were from Roth (Karlsruhe, Germany). PCR primers were synthesized by Life Technologies Invitrogen. The primary antibody against Sepp1 and the secondary HRP-coupled anti-goat IgG antibody were from Santa Cruz Biotechnology. The primary antibody against $\beta$-actin was from Sigma, and the secondary HRP-coupled anti-mouse IgG antibody was from Dianova (Hamburg, Germany).

\section{Cell culture}

The rat insulinoma cell line INS-1 (Asfari et al. 1992) was a kind gift of Dr J Seissler (Ludwig Maximilians University, Munich, Germany). INS-1 cells were cultured at $37{ }^{\circ} \mathrm{C}$ in a humidified $5 \% \mathrm{CO}_{2}$ atmosphere in RPMI 1640 medium (Sigma) supplemented with 10\% FCS (PAA; Pasching, Austria), 100 units/ml penicillin, $100 \mu \mathrm{g} / \mathrm{ml}$ streptomycin (PAA), $2 \mathrm{mM}$ glutamax (Invitrogen), and $50 \mu \mathrm{M}$ 2-mercaptoethanol (Sigma) as described previously (Schinner et al. 2008). For experiments, cells were cultured in serum-free medium supplemented with $1 \mu \mathrm{M}$ Se (sodium selenite, sodium selenate, or selenomethionine) and glucose $(5,11$, or $16.7 \mathrm{mM}$ ) for $24 \mathrm{~h}$. Cytotoxicity of the applied Se compounds was assessed by determining the percentage of metabolically active INS-1 cells using the CellTiter $96 \mathrm{AQ}_{\mathrm{ueous}}$ nonradioactive cell proliferation assay (Promega) according to the manufacturer's protocol.

\section{Sample collection from animals}

Animals were obtained from the animal facility of the University Hospital Duesseldorf. The protocols were conducted in accordance with the principles of laboratory care. Islets were prepared from 2-month-old C57BL/6 mice. Mice were killed and islets were isolated using the intraductal collagenase digestion technique as described

Published by Bioscientifica Ltd. 
previously (Schinner et al. 2008). Islets were purified, handpicked, and thereafter incubated for $24 \mathrm{~h}$ in KrebsRinger buffer (Sigma) containing different glucose concentrations. Samples of pancreas, liver, and kidney were taken from Wistar rats. Rats were killed and tissues were removed and frozen immediately in liquid nitrogen.

\section{Treatment of mice with the $\beta$-cell toxin STZ}

Four-week-old C57BL/6 mice received $40 \mathrm{mg} \mathrm{STZ/kg} \mathrm{body}$ weight by i.p. injections on 5 consecutive days, according to a previously described low-dose STZ protocol (Lu et al. 1998). Blood glucose concentrations were measured weekly. Two weeks after STZ injection, mice became diabetic as indicated by a rise in blood glucose concentrations to $\geq 17 \mathrm{mM}$. Mice were killed at different time points 1-2 weeks after STZ injection, displaying blood glucose concentrations from 8.0 to $18.6 \mathrm{mM}$. Pancreata were removed and frozen in liquid nitrogen for histological staining.

\section{Real-time RT-PCR}

From INS-1 cells and rat tissues, total RNA was isolated using the RNeasy Mini Kit (Qiagen) and transcribed into cDNA using SuperScript II reverse transcriptase (Invitrogen). From mouse islets, total RNA was extracted using the RNeasy Plus Micro Kit (Qiagen) and transcribed with the High-Capacity cDNA Reverse Transcription Kit (Life Technologies Applied Biosystems). Analysis of mRNA expression was done in a LightCycler 2.0 qPCR system (Roche). PCR was performed with $40 \mathrm{ng}$ cDNA in glass capillaries containing LightCycler FastStart DNA Master SYBR Green I Reaction Mix (Roche), $3 \mathrm{mM} \mathrm{MgCl}$, and $1 \mu \mathrm{M}$ primers. PCR amplicons were quantified by the LightCycler software, employing the housekeeping gene hypoxanthine phosphoribosyltransferase 1 ((HPRT) HPRT1) for internal normalization as described (Speckmann et al. 2008). Primers were designed using the Universal ProbeLibrary Assay Design Center (Roche), and their specificity was confirmed by melting curve analysis and agarose gel electrophoresis of PCR products. The PCR product sizes and primer sequences were as follows: rat GPx1 (PCR product: 60 bp): F: CGACATCGAACCCGATATAGA, R: ATGCCTTAGGGGTTGCTAGG; rat HPRT1 (PCR product: $61 \mathrm{bp}$ ): F: GACCGGTTCTGTCATGTCG, R: ACCTGGTTCATCATCACTAATCAC; rat Sepp1 (PCR product: $73 \mathrm{bp}$ ): F: GACAGTGGTTGCTCTTCTTCAA, R: TCGCAGGTCTTCCAATCTG; mouse HPRT1 (PCR product: $90 \mathrm{bp}$ ): F: TCCTCCTCAGACCGCTTTT, R:
CCTGGTTCATCATCGCTAATC; and mouse Sepp1 (PCR product: $125 \mathrm{bp}$ ): F: GGTGCGGAAACTGCAATC, R: TTTGTTGTGGTGT-TTGTGGTG.

\section{Immunoblotting}

Whole-cell lysates were obtained by treatment of INS-1 cells with $1 \%$ SDS. The protein content of the lysates was determined by DC Protein Assay (Bio-Rad). Culture supernatants of INS-1 cells were concentrated 40-fold by ultrafiltration using Vivaspin 2 concentrator columns (Sartorius, Göttingen, Germany) as described (Steinbrenner et al. 2006). Immunoblotting was performed by standard techniques as described (Speckmann et al. 2008). Briefly, aliquots of $20-35 \mu \mathrm{g}$ protein or equal aliquots of INS-1 supernatants were separated on $10 \%$ SDS-PAGE gels followed by electroblotting onto PVDF membranes (GE Healthcare, Freiburg, Germany). After blocking unspecific binding sites with Tris-buffered saline Tween 20 (TBST) $/ 5 \%$ milk powder (Roth), membranes were incubated with primary and secondary antibodies diluted in blocking buffer. Immunodetection was carried out with SuperSignal West Pico Chemiluminescent Substrate (Thermo Scientific Pierce, Waltham, MA, USA) and X-ray film (GE Healthcare).

\section{Plasmids and luciferase reporter gene assay}

Sequence information on the rat Sepp1 gene was obtained from the Rat Genome Database (Twigger et al. 2007). A 1500-bp genomic DNA fragment located immediately upstream of the translation start site of the predominant rat Sepp1 transcript variant 1 (GenBank accession number: NM_019192) was cloned into the firefly luciferase reporter gene vector pGL3basic (Promega). Genomic DNA was isolated from INS-1 cells with PureLink Genomic DNA Mini Kit (Invitrogen) and subjected to PCR using Pfu DNA polymerase (Fermentas, St Leon-Rot, Germany) and the primers $5^{\prime}$-ATCAAGTCCGTTTACATTTCC-3' (sense) and 5'-AACCCCTTCAGACTAGCTTG-3' (antisense). The PCR product served as template in a subsequent PCR with primers carrying recognition sites for $\mathrm{KpnI}$ and XhoI restriction enzymes. After restriction digest, the product of this second PCR was cloned into the KpnI and XhoI restriction sites of pGL3basic. The resulting plasmid construct was sequenced and termed ratSepp1-luc. The DNA sequence of the putative rat Sepp1 promoter fragment $(-1904 /-16)$ was submitted to GenBank (accession number: JQ082498). For reporter gene assays, INS-1 cells grown in 24-well plates were co-transfected

Published by Bioscientifica Ltd. 
with $0 \cdot 5 \mu \mathrm{g}$ ratSepp1-luc plasmid and $0 \cdot 1 \mu \mathrm{g}$ renilla luciferase pRL-TK plasmid (Promega) together with $3 \cdot 2 \mu \mathrm{l}$ nanofectamin (PAA) according to the manufacturer's protocol. The promoter/enhancer-less firefly luciferase vector pGL3basic was co-transfected with pRL-TK in control experiments for the determination of background promoter activity. Twenty-four hours after transfection, luciferase activities were determined by chemiluminescence detection in a Victor 1420 multi-label counter (Perkin Elmer Wallac, Waltham, MA, USA) using the Dual Luciferase Reporter Assay (Promega) as described (Schinner et al. 2008, Speckmann et al. 2008).

\section{Immunohistochemistry and immunofluorescence}

For immunohistochemistry analysis, pancreata of C57BL/6 mice were sliced and frozen. Cryosections were fixed with acetone at $-20^{\circ} \mathrm{C}$. Thereafter, the sections were washed thrice with TBST. Sections were blocked according to the secondary antibody used: for insulin and glucagon staining, sections were blocked with avidin (Dako, Hamburg, Germany) for $10 \mathrm{~min}$ and then with peroxidase blocking solution (Dako). For Sepp1 staining, sections were blocked with peroxidase blocking solution only. Thereafter, 5\% normal swine serum (in aqua dest.) was applied. Primary antibodies against Sepp1 (C-14, sc-22639; Santa Cruz; 1:50), insulin (Dako; 1:50), or glucagon (GeneTex, Inc., Irvine, CA, USA; 1:10) were incubated overnight at $4{ }^{\circ} \mathrm{C}$. For negative controls, the primary antibody was omitted. Subsequently, sections were washed thrice with TBST for $5 \mathrm{~min}$ and incubated for $60 \mathrm{~min}$ at room temperature with the respective secondary antibodies (Sepp1: anti-goat IgG-HRP, Santa Cruz, 1:200; insulin: anti-guinea pig IgG-HRP, Dako, 1:150; glucagon: anti-rabbit IgG-biotin, AbD Serotec, 1:400). For staining, the VECTASTAIN Elite ABC kit (Vector, Burlingame, CA, USA) was applied together with AEC chromogenic substrate (Dako). Counterstaining was performed for 1 min in hematoxylin II.

For immunofluorescence analysis, cryosections were fixed in acetone, air dried, washed three times with TBST, and blocked with 5\% normal swine serum for $60 \mathrm{~min}$. Thereafter, primary antibodies against insulin (1:400), glucagon (1:10), or Sepp1 (1:50) were applied overnight at $4{ }^{\circ} \mathrm{C}$. The next day, sections were washed thrice with TBST for 5 min and incubated with Alexa Fluor-coupled secondary antibodies (Invitrogen) at a 1:1500 dilution. Digital images were produced using a Nikon Eclipse TE300 microscope equipped with a Nikon DXM1200 camera (Nikon, Tokyo, Japan).

\section{Statistical analysis}

Values are given as mean \pm s.D. of three or more independent experiments. Differences between groups were tested for significance by Student's $t$-test with ${ }^{*} P<0 \cdot 05$, ${ }^{* *} P<0 \cdot 01$, and ${ }^{* * *} P<0 \cdot 001$ as levels of significance.

\section{Results}

\section{Pancreatic expression and localization of Sepp1}

Pancreatic $\beta$-cells are relatively deficient in three major antioxidant enzymes: catalase, GPx, and SOD (Tiedge et al . 1997). We hypothesized that $\beta$-cells may possess an additional antioxidant protein, Sepp1, as the presence of Sepp 1 mRNA has been demonstrated before in the rodent pancreas and in $\beta$-cells (Niwa et al. 1997, Lee et al. 2008). As both Sepp1 and GPx1 mRNA have been detected in liver and kidney at high copy numbers (Hoffmann et al. 2007), we first compared their gene expression in liver, kidney, and pancreas taken from rats fed a Se-adequate standard diet. Gene expression of both selenoproteins was in the following order: liver $>$ kidney $>$ pancreas. In pancreas, Sepp1 was expressed relatively higher than GPx1. Sepp 1 mRNA levels in rat pancreas were 58\%, whereas pancreatic GPx1 mRNA levels were only $22 \%$ of the liver values (Fig. 1 ).

In order to examine the localization of Sepp1 in pancreas, we performed staining of mouse pancreas sections by means of fluorescence microscopy. This revealed that pancreatic Sepp1 expression is restricted to

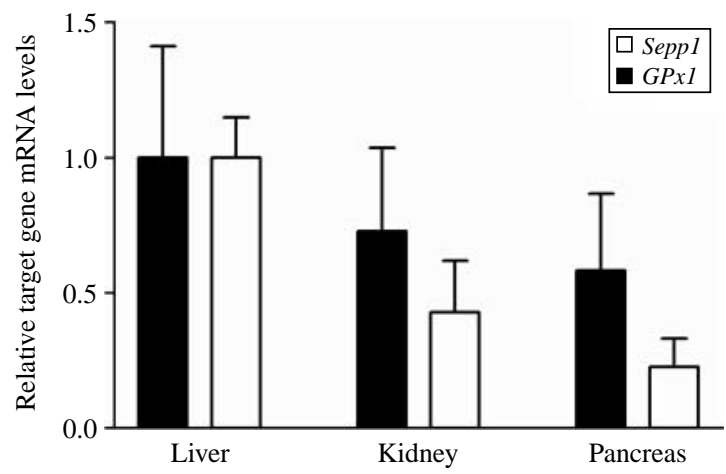

Figure 1

Relative gene expression of Sepp1 and GPx1 in rat tissues. Sepp1 and GPX1 mRNA levels were analyzed by real-time RT-PCR and normalized against HPRT1. Data are given as mean \pm s.E.M. from three animals. Sepp1 and GPX1 mRNA levels in pancreas and kidney were calculated in relation to the values in liver set as $100 \%$.

Published by Bioscientifica Ltd. 
the islets, where Sepp1 appears to be co-localized with both insulin and glucagon (Fig. 2A, B and C). Consistently, immunohistochemistry analysis of mouse pancreas sections demonstrated Sepp1 expression in both glucagonproducing $\alpha$-cells and insulin-producing $\beta$-cells of the pancreatic islets, whereas no Sepp1 staining was observed in the exocrine pancreas tissue (Supplementary Figure 1a, $\mathrm{b}$ and $\mathrm{c}$, see section on supplementary data given at the end of this article).

\section{Downregulation of Sepp1 in pancreatic $\beta$-cells by high glucose}

Next, we investigated the influence of dietary Se compounds and glucose on biosynthesis of Sepp1 in $\beta$-cells in vitro, using the glucose-responsive rat insulinoma cell line INS-1 (Asfari et al. 1992). Biosynthesis of many selenoproteins depends on adequate Se supply (Steinbrenner \& Sies 2009), and consequently, various Se compounds have been shown to stimulate Sepp1 production in hepatocytes with sodium selenite being the most efficient Se donor (Hoefig et al. 2011). As high concentrations of Se compounds may decrease the viability of cultured cells, we first examined the cytotoxicity of three commonly ingested dietary Se compounds in INS-1 cells by MTS assay. Sodium selenate and selenomethionine did not impair the metabolic activity of INS-1 cells up to concentrations of $100 \mu \mathrm{M}$. Sodium selenite was considerably more cytotoxic, as it lowered the metabolic activity to $50 \%$ when applied at a concentration of $10 \mu \mathrm{M}$ for $24 \mathrm{~h}$ (Fig. 3). Thus, we treated the INS- 1 cells with $1 \mu \mathrm{M}$ of the Se compounds to exclude toxic effects while ensuring sufficient Se supply for biosynthesis of selenoproteins.

Each of the three applied Se compounds significantly upregulated Sepp1 gene expression in INS-1 cells cultured under normoglycemic conditions ( $5 \mathrm{mM}$ glucose). The strongest stimulatory effect was elicited by treatment with $1 \mu \mathrm{M}$ selenate, yielding a $2 \cdot 8$-fold increase in Sepp $1 \mathrm{mRNA}$ levels compared with Se-deficient controls (Fig. 4A). In order to test for the influence of hyperglycemia, we compared Sepp1 gene expression in INS-1 cells exposed to Se compounds in culture medium containing 5,11 , or 16.7 mM glucose. High glucose concentrations dose dependently suppressed the Se-induced elevation of Sepp1 gene expression. Irrespective of the applied Se compound, a significant attenuation of Sepp1 mRNA levels was observed at $16.7 \mathrm{mM}$ glucose in comparison to $5 \mathrm{mM}$ glucose (Fig. $4 \mathrm{~A}$ ).

We examined whether Se and glucose may influence Sepp1 promoter activity. From isolated genomic DNA of
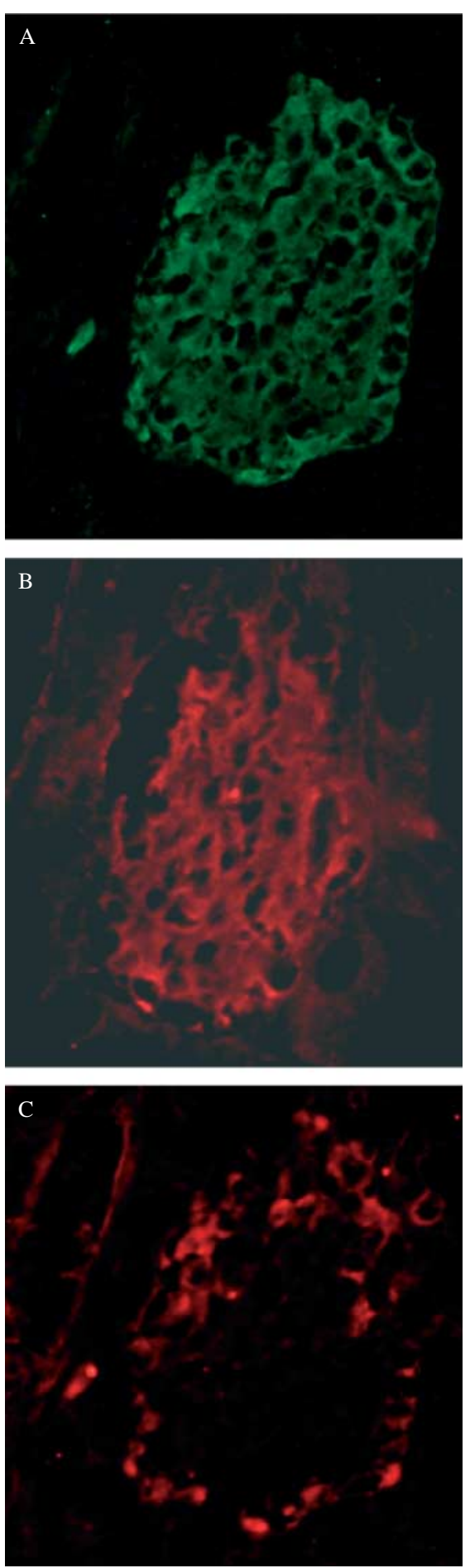

\section{Figure 2}

Localization of selenoprotein $P$ in mouse pancreatic islets. Sections from pancreas of C57BL/ 6 mice were analyzed by immunofluorescence staining for Sepp1 (green) (A), insulin (red) (B), and glucagon (red) (C).

Published by Bioscientifica Ltd. 


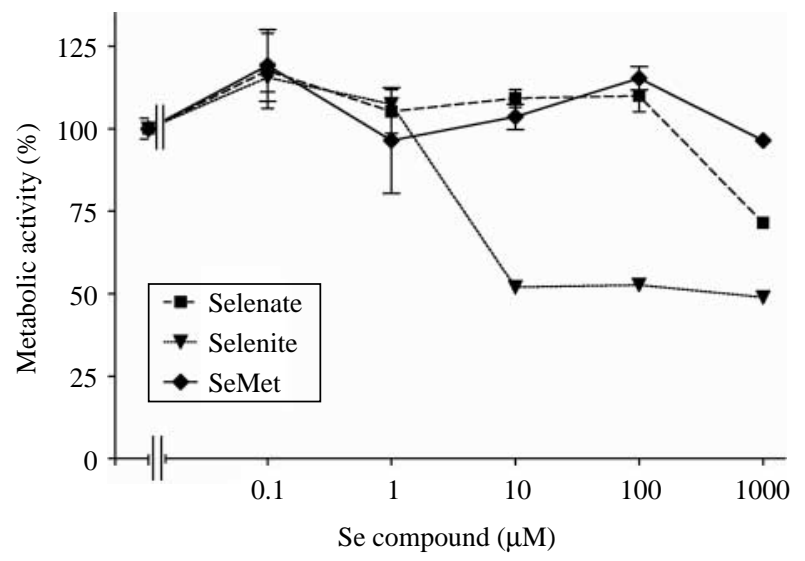

Figure 3

Influence of selenium compounds on the metabolic activity of INS-1 rat insulinoma cells. INS-1 cells were treated for $24 \mathrm{~h}$ with sodium selenate, sodium selenite, or L-selenomethionine (SeMet) at the indicated concentrations, and a MTS assay was performed. The metabolic activity of mocktreated cells cultured in serum-free medium was set as $100 \%$. Experiments were performed in triplicate; the data represent mean \pm s.E.M.

INS-1 cells, a $1500 \mathrm{bp}$ fragment located immediately upstream of the translation start site of the predominantly expressed transcript variant 1 of rat Sepp1 was cloned into a luciferase reporter gene vector. The cloned rat Sepp1 promoter region was chosen according to the sequence of the human Sepp1 promoter region (GenBank accession number: Y12262) (Dreher et al. 1997). As previously described for the human Sepp1 promoter (Dreher et al. 1997, Speckmann et al. 2008), the rat Sepp1 promoter contains a TATA motif, suggesting Sepp1 transcription by RNA polymerase II, and a combined binding site for hepatocyte nuclear factor $4 \alpha$ (HNF- $4 \alpha$ ) and forkhead box O1a (FoxO1a), required for high-level Sepp1 expression in hepatocytes. Sepp1 promoter activity in INS-1 cells was not significantly altered by Se, whereas high glucose concentrations (11 or $16.7 \mathrm{mM}$ glucose) significantly inhibited Sepp1 promoter activity when applied together with selenate (Fig. 4B).

As the strongest alterations of Sepp1 mRNA levels and promoter activity in INS-1 cells were observed with selenate and high glucose (Fig. 4A and B), we investigated the influence of these stimuli on Sepp1 protein expression. Intracellular Sepp1 levels were elevated by selenate under normoglycemic conditions, and high glucose concentrations (11 and $16 \cdot 7 \mathrm{mM}$ glucose) suppressed the stimulatory effect of selenate. However, these changes of Sepp1 protein expression did not reach statistical significance due to high variation between the experiments (Fig. 4C).
The molecular weight of Sepp1 detected in INS-1 cell lysates corresponds to the $45 \mathrm{kDa}$-Sepp 1 isoform previously described in human astrocytes and mouse adipocytes (Steinbrenner et al. 2006, Zhang \& Chen 2011). As Sepp1 is primarily known as an extracellular protein (Burk \& Hill 2009), we tested INS-1 culture supernatants for the presence of Sepp1. However, we did not detect any secreted Sepp1 isoforms, even in 40-fold concentrated INS-1 supernatants (data not shown).

In order to verify the observed inhibitory effect of glucose on Sepp1 expression in $\beta$-cells, we exposed primary islets isolated from mouse pancreas to increasing glucose concentrations within a range from $2.75 \mathrm{mM}$ (hypoglycemic) to $22 \mathrm{mM}$ (severely hyperglycemic) and analyzed Sepp1 mRNA levels by real-time RT-PCR. In comparison with $5.5 \mathrm{mM}$ glucose, Sepp1 gene expression in islets was not altered at $2.75 \mathrm{mM}$ glucose but significantly downregulated to $76 \%$ at $11 \mathrm{mM}$ glucose and to $72 \%$ at $22 \mathrm{mM}$ glucose respectively (Fig. 5).

High glucose is known to affect RNA stability in $\beta$-cells, including the stability of insulin mRNA (Welsh et al. 1985). To explore whether Sepp1 mRNA is degraded faster at elevated glucose concentrations, we treated INS-1 cells with the transcription inhibitor actinomycin D. Addition of actinomycin D lowered Sepp1 mRNA levels, and this was more pronounced under hyperglycemic conditions: after $20 \mathrm{~h}$ of treatment with actinomycin $\mathrm{D}$, Sepp1 mRNA levels were decreased to $36 \%$ at $5 \mathrm{mM}$ glucose and to $12 \%$ at $16.7 \mathrm{mM}$ glucose respectively (Fig. 6). Thus, high glucose appears to destabilize Sepp1 mRNA in $\beta$-cells.

\section{Alterations in pancreatic Sepp1 expression in STZ-treated mice}

STZ is frequently used to induce diabetes in animal models. STZ causes necrosis of the insulin-producing $\beta$-cells that is primarily mediated by DNA alkylation (Lenzen 2008). In addition, STZ has been shown to induce oxidative/nitrosative stress by generation of superoxide and NO (Nukatsuka et al. 1988, Turk et al. 1993). To examine the effect of this $\beta$-cell toxin on pancreatic Sepp1 expression, C57BL/6 mice were treated with $40 \mathrm{mg} \mathrm{STZ/kg}$ body weight. Blood glucose concentrations were measured every second day. The animals were killed 1 or 2 weeks respectively after STZ treatment. Mice became prediabetic 1 week after STZ treatment, exhibiting fasting blood glucose concentrations from $8 \cdot 0$ to $14 \cdot 7 \mathrm{mM}$. After 2 weeks, mice became diabetic with blood glucose concentrations ranging from $17 \cdot 0$ to $18.6 \mathrm{mM}$. Sepp1

Published by Bioscientifica Ltd. 
expression in pancreatic islets was investigated by histological staining. Pancreatic Sepp1 expression was elevated after short-term (7 days) exposure to STZ (blood glucose: $8.0 \mathrm{mM}$ ) (Fig. $7 \mathrm{~B}$ and $\mathrm{C}$ ). In the long term, pancreatic Sepp1 expression decreased concomitantly with the progressive loss of $\beta$-cell mass and resulting increases in blood glucose concentrations after STZ treatment (Fig. 7D and E).
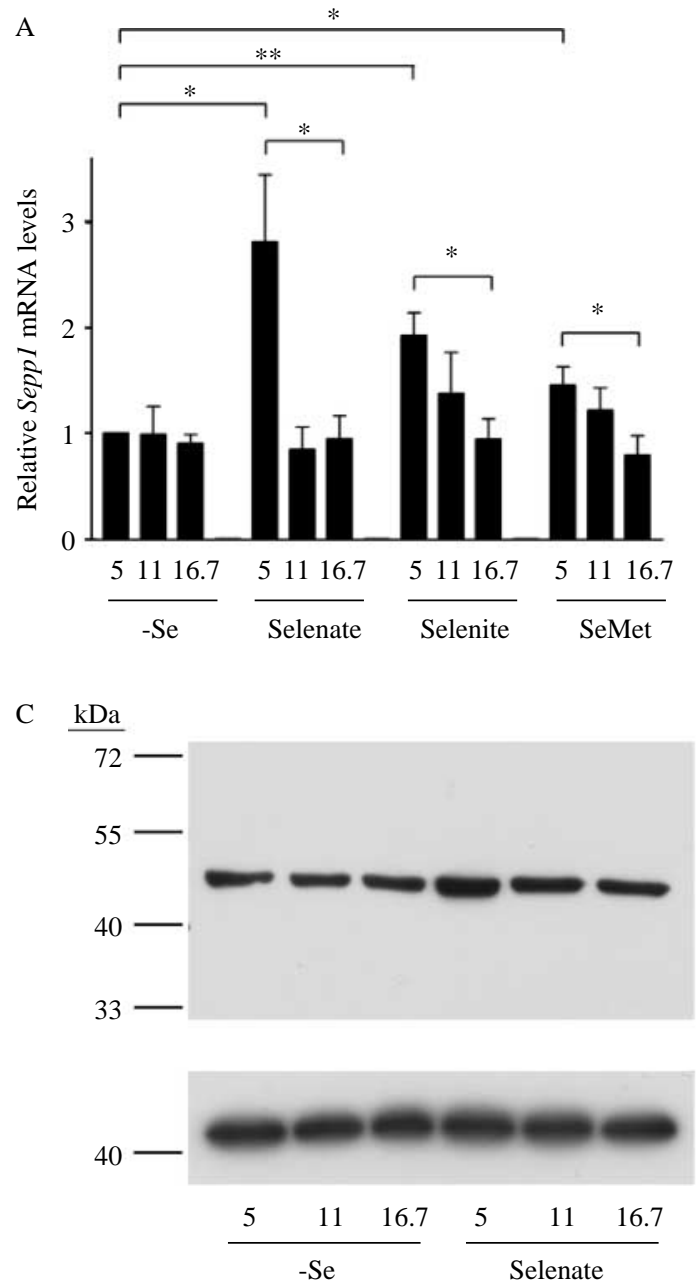

Figure 4

Modulation of Sepp1 expression in INS-1 rat insulinoma cells by selenium compounds and glucose. INS-1 cells were cultured for $24 \mathrm{~h}$ in serum-free medium (-Se) or treated with $1 \mu \mathrm{M}$ of the indicated Se compound in combination with glucose at the indicated concentrations. (A) Relative Sepp1 mRNA levels were determined by real-time RT-PCR, using HPRT1 for normalization. Data represent mean \pm s.E.M. of three independent experiments $\left({ }^{*} P<0.05, * * P<0.01\right)$. (B) INS-1 cells were cultured as in Fig. 3 and co-transfected with a luciferase reporter gene construct containing the rat SeP promoter (ratSepp1-luc) together with a renilla luciferase plasmid (pRL-TK). Twenty-four hour posttransfection, luciferase activity was
In order to explore whether STZ affects Sepp1 expression in $\beta$-cells in vitro, we treated INS-1 cells with STZ (0.5 mM) for $24 \mathrm{~h}$. However, Sepp1 mRNA levels were not significantly altered by STZ, neither in Se-deficient nor in selenate-supplemented INS-1 cells (data not shown). On the other hand, selenate protected INS-1 cells to some extent from cell death induced by $1 \mathrm{mM}$ STZ (Supplementary Figure 2, see section on supplementary data given
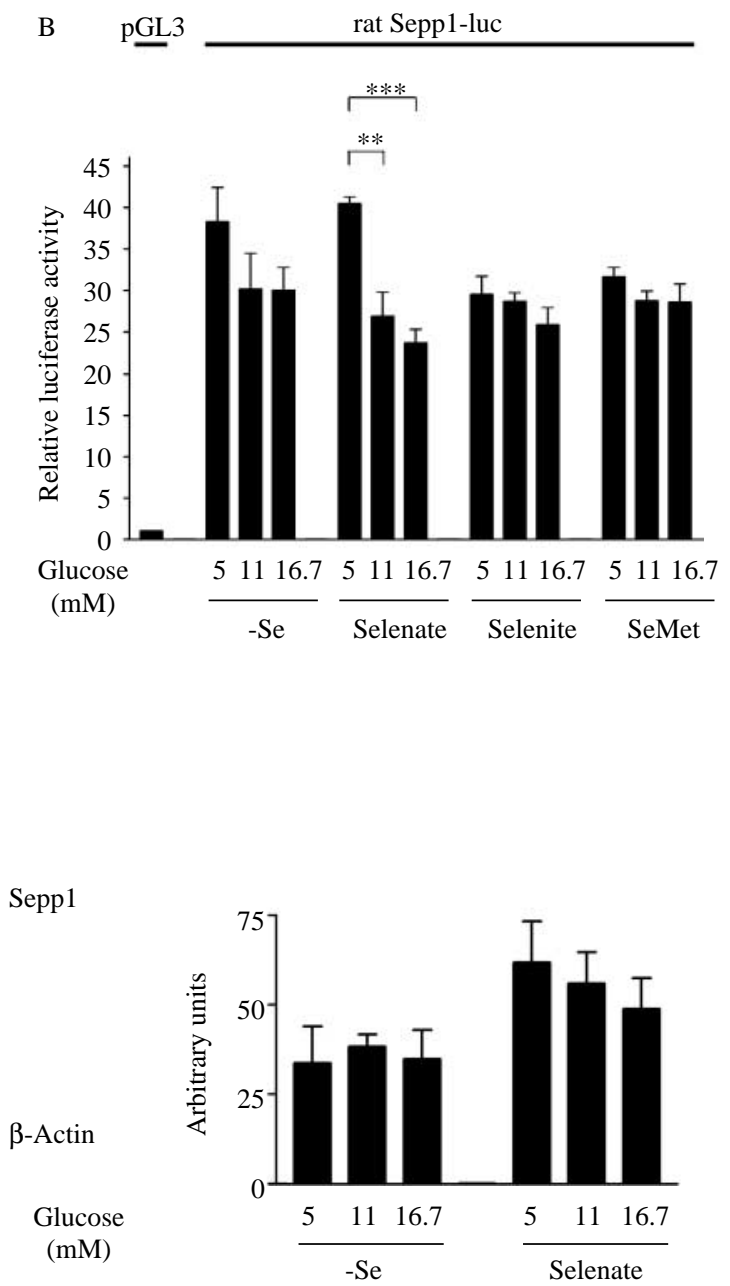

analyzed in cell lysates. Values are normalized to the activity of the promoter/enhancer-less luciferase construct pGL3. Data are given as mean \pm S.E.M. of three to five independent experiments $(* * P<0.01$, $\star * \star P<0.001)$. (C) INS-1 cells were cultured for $24 \mathrm{~h}$ in serum-free medium (-Se) or treated with $1 \mu \mathrm{M}$ sodium selenate in combination with glucose at the indicated concentrations. Sepp1 protein levels were determined in immunoblots of cell lysates, using $\beta$-actin as loading control. A representative blot out of three experiments is shown (left part). Densitometric analysis of three independent experiments; data are given as mean \pm S.E.M. (right part).

Published by Bioscientifica Ltd. 


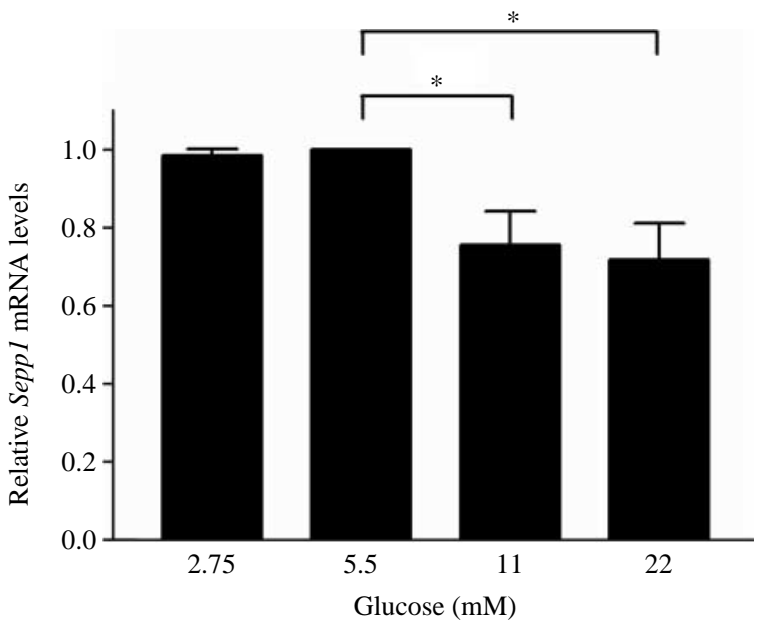

Figure 5

High glucose downregulates SeP mRNA expression in mouse islets. Isolated mouse islets were cultured in Krebs-Ringer buffer with the indicated concentrations of glucose for $24 \mathrm{~h}$. Sepp $1 \mathrm{mRNA}$ levels were analyzed by real-time RT-PCR, normalized against HPRT1, and calculated in relation to $5.5 \mathrm{mM}$ glucose. Data are given as mean \pm s.E.M. from three independent experiments $\left({ }^{*} P<0.05\right)$

at the end of this article). This suggests that other selenoproteins might be involved in selenate-mediated protection against STZ-induced $\beta$-cell death. For example, GPx1 has long been known to be induced by Se supplementation (Steinbrenner \& Sies 2009) and GPx1 overexpression protected transgenic mice from STZinduced $\beta$-cell destruction (Harmon et al. 2009).

\section{Discussion}

Superoxide and $\mathrm{H}_{2} \mathrm{O}_{2}$ fulfill a dual role in cellular metabolism: low levels serve as second messengers in intracellular signaling cascades but high levels may provoke dysfunction and cell death. In pancreatic $\beta$-cells, this notion is exemplified by the action of $\mathrm{H}_{2} \mathrm{O}_{2}$ on glucose-stimulated insulin secretion (GSIS). While a glucose-induced increase in intracellular $\mathrm{H}_{2} \mathrm{O}_{2}$ generation is required as a metabolic signal for GSIS (Pi et al. 2007), oxidative stress derived from exposure to high concentrations of $\mathrm{H}_{2} \mathrm{O}_{2}$ blunts GSIS in islets and INS-1 insulinoma cells (Maechler et al. 1999). Oxidative stress is also thought to be involved in the deleterious effects of chronic hyperglycemia on $\beta$-cell function and integrity, termed glucotoxicity (Poitout \& Robertson 2008, Kim \& Yoon 2011). Thus, proper regulation of the cellular redox balance is of prime importance to maintain and adapt pancreatic insulin production and secretion. Low expression and activity of major antioxidant enzymes such as catalase, SOD, and GPx may render $\beta$-cells particularly sensitive to signaling as well as to cytotoxic actions of ROS (Tiedge et al. 1997, Pi et al. 2007, Lei \& Vatamaniuk 2011).

In this study, we demonstrate that $\beta$-cells express an additional antioxidant protein, Sepp1. Purified Sepp1 has been shown to reduce PH in vitro, although exhibiting lower reactivity than PH-GPx (Takebe et al. 2002). Endogenous Sepp1 in $\beta$-cells may thus participate in protection of components of the plasma membrane from oxidative damage. As Sepp1 contains up to ten Se atoms (Burk \& Hill 2009), it might also serve as cellular Se pool that provides Se for the biosynthesis of selenoenzymes such as GPx. Sepp1 protein expression in pancreas appears to be restricted to islets, where Sepp1 was co-localized with both insulin ( $\beta$-cells) and glucagon ( $\alpha$-cells) (Fig. 2). In INS-1 insulinoma cells, we found no evidence for secretion of Sepp1. Instead, INS-1 cells produce intracellularly localized Sepp1 that runs in immunoblots as a single band of $\sim 45 \mathrm{kDa}$ (Fig. 4C). We described previously a similar pattern of Sepp1 expression in cultured astrocytes, containing Sepp1 in the form of a non-glycosylated membrane-associated protein (Steinbrenner et al. 2006). Two intracellular Sepp1 isoforms with molecular weights of $\sim 40$ and $\sim 45 \mathrm{kDa}$ have been detected in adipocytes, where Sepp1 appears to be required for adipogenic

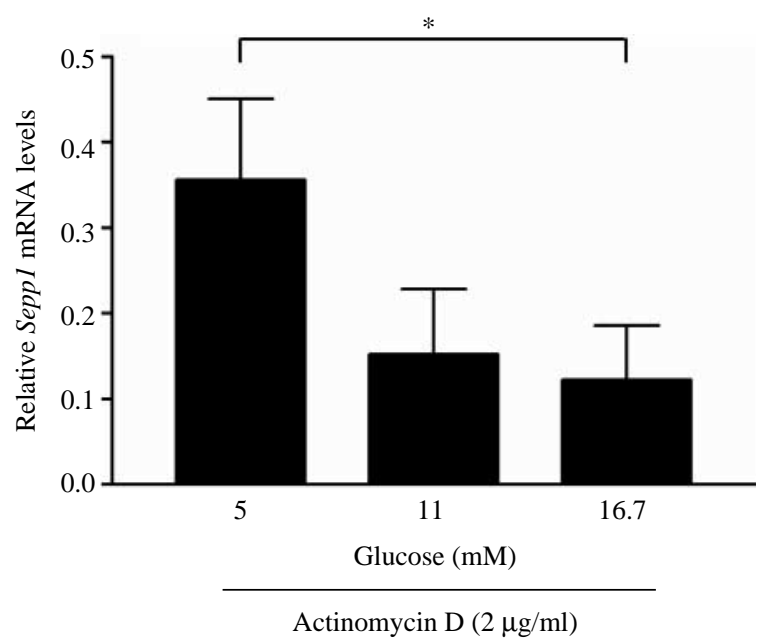

Figure 6

High glucose destabilizes Sepp 1 mRNA in INS-1 cells. INS-1 cells were cultured for $20 \mathrm{~h}$ in serum-free medium supplemented with glucose at the indicated concentrations and treated with actinomycin D $(2 \mu \mathrm{g} / \mathrm{ml})$. Sepp 1 mRNA levels were determined by real-time RT-PCR, using HPRT1 for normalization. Values were calculated in relation to Sepp1 mRNA levels in INS- 1 cells cultured at $5 \mathrm{mM}$ glucose without addition of actinomycin D. Data are given as mean \pm S.E.M. from five independent experiments $\left({ }^{*} P<0.05\right)$.

Published by Bioscientifica Ltd. 

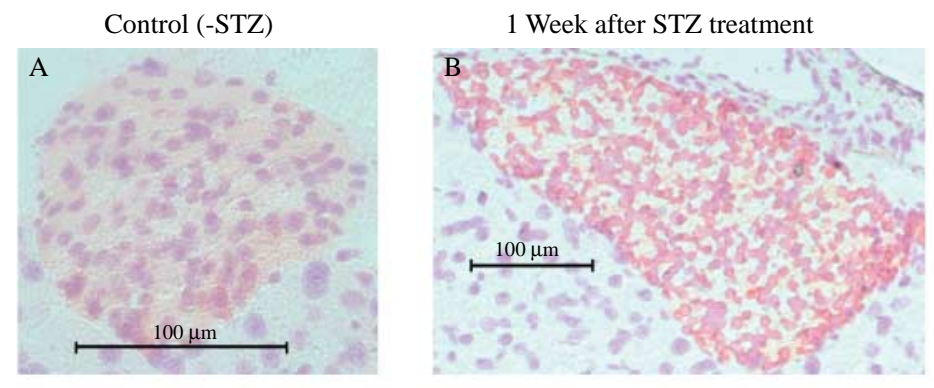

(Blood glucose: $8.0 \mathrm{mM}$ )

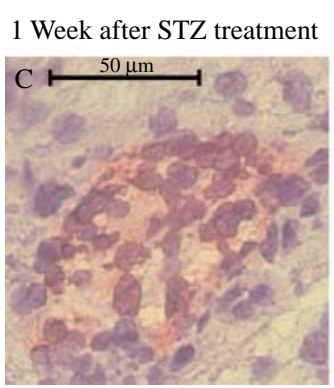

(Blood glucose: $13.0 \mathrm{mM}$ )

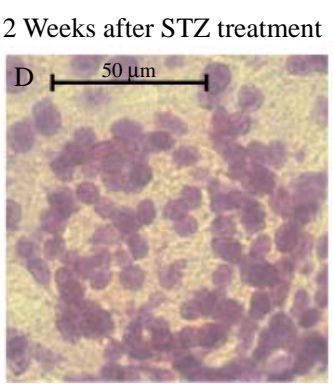

(Blood glucose: $17.0 \mathrm{mM}$ )

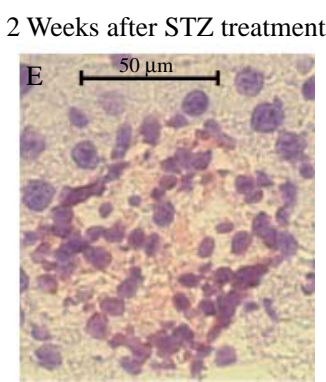

(Blood glucose: $18.6 \mathrm{mM}$ )

\section{Figure 7}

Modulation of pancreatic Sepp1 expression after STZ treatment of mice. Sections from pancreas of C57BL/6 mice treated with $40 \mathrm{mg} \mathrm{STZ/kg} \mathrm{body}$ weight were analyzed by immunohistochemistry for the presence of Sepp1

differentiation (Zhang \& Chen 2011). By contrast, hepatocytes and enterocytes secrete up to four highly glycosylated Sepp1 isoforms (Ma et al. 2002, Speckmann et al. 2010).

Biosynthesis of Sepp1 in hepatocytes depends on the availability of the micronutrient Se (Burk \& Hill 2009). Consistently, we show here that dietary Se compounds increase expression of Sepp1 in INS-1 cells (Fig. 4). Se has been reported to influence $\beta$-cell function: sodium selenite and selenate stimulated biosynthesis and secretion of insulin in Min6 insulinoma cells and isolated rat islets in vitro, probably by increasing intracellular GPX activity (Campbell et al. 2008). Paradoxically, elevated expression/activity of the selenoenzyme GPx1 in $\beta$-cells can elicit opposing metabolic outcomes in vivo (Lei \& Vatamaniuk 2011). $\beta$-Cells of mice with global transgenic overexpression of GPx1 are hypertrophic, showing upregulated expression of pancreatic duodenal homeobox 1 (PDX1) transcription factor and elevated insulin production and secretion. These alterations were not beneficial but resulted in hyperinsulinemia, insulin resistance, and obesity in aged animals (McClung et al. 2004, Wang et al. 2008). On the other hand, $\beta$-cell-specific overexpression of
(A) nontreated control (B) and (C) Sepp1 detection 1 week after STZ treatment (D) and (E) Sepp1 detection 2 weeks after STZ treatment. Blood glucose concentrations of the STZ-treated animals are given in parentheses.

GPx1 ameliorated hyperglycemia in $d b / d b$ mice and in STZ-treated mice (Harmon et al. 2009). Moreover, an adaptive increase in expression levels of antiapoptotic proteins and antioxidant enzymes including GPx1 has been proposed to contribute to survival of hypertrophic $\beta$-cells during chronic hyperglycemia (Laybutt et al. 2002).

As hepatic gene expression and secretion of Sepp 1 is increased at high glucose concentrations (Speckmann et al. 2009, Misu et al. 2010), we hypothesized that glucose may affect Sepp1 levels in $\beta$-cells as well. In contrast to hepatocytes, high glucose (11-22 mM) downregulated Sepp1 gene expression in isolated islets and decreased Sepp1 promoter activity, mRNA levels, and mRNA stability in INS-1 cells (Figs 4, 5 and 6). Consistently, exposure of isolated islets to high glucose has been shown to downregulate peroxisomal proliferator-activated receptor- $\gamma$ coactivator $1 \alpha$ (PGC-1 $\alpha$; Zhang et al. 2005), a transcriptional coactivator that is required for high-level gene expression of Sepp1 (Speckmann et al. 2008). Prolonged hyperglycemia causes dedifferentiation of $\beta$-cells, characterized by loss of GSIS, upregulated expression of glycolytic enzymes, and downregulated expression of insulin and $\beta$-cell-specific transcription factors such as

Published by Bioscientifica Ltd. 
PDX1 (Weir \& Bonner-Weir 2004, Kim \& Yoon 2011). A differentiation-triggered increase in Sepp1 biosynthesis has been observed in intestinal epithelial cells and adipocytes (Speckmann et al. 2010, Zhang \& Chen 2011). Conversely, the decrease in pancreatic Sepp1 expression at high glucose concentrations may derive from dedifferentiation of $\beta$-cells, induced by glucotoxicity. High glucose has been demonstrated to induce the biosynthesis of thioredoxin-interacting protein (Txnip) in pancreatic $\beta$-cells (Minn et al. 2005). Txnip modulates the cellular redox state by binding and inactivating thioredoxin (Nishiyama et al. 1999). Thioredoxin is the preferred electron donor for Sepp1, being 500-fold more effective than glutathione as cofactor for the GPx-like activity of Sepp1 (Takebe et al. 2002). Thus, both Sepp1 and its cofactor thioredoxin appear to be repressed in $\beta$-cells under hyperglycemic conditions.

To explore the effect of hyperglycemia on pancreatic Sepp1 expression in vivo, we applied an animal model of diabetes induction through the $\beta$-cell toxin STZ. Expression of the $\mathrm{H}_{2} \mathrm{O}_{2}$-degrading enzymes peroxiredoxin 1 and peroxiredoxin 2 has been reported to be elevated upon STZ treatment of INS-1 cells (Bast et al. 2002). We observed an STZ-induced increase in pancreatic Sepp1 protein levels that lasted as long as blood glucose concentrations remained within the normoglycemic range (Fig. 7). In the long term, progressive $\beta$-cell loss and elevated blood glucose concentrations were accompanied by a decrease in Sepp1 expression, suggesting that an adaptive antioxidant response is not sufficient to prevent STZinduced $\beta$-cell death. As shown by other groups (Takeda et al. 2012), low-dose STZ leads to $\alpha$-cell expansion and elevated glucagon levels in the pancreas. Therefore, it cannot be ruled out that Sepp1 expression after STZ treatment localizes to $\alpha$-cells. However, the expression of Sepp1 in islets is enriched in $\beta$-cells compared with $\alpha$-cells (Niwa et al. 1997), suggesting that the expression of Sepp1 in the remaining islet cells is most probably in $\beta$-cells.

Taken together, this study provides evidence for the presence of Sepp1 in pancreatic islets and $\beta$-cells. Our data suggest that Sepp1 may have a role in antioxidant protection of $\beta$-cells and that its downregulation under hyperglycemic conditions might contribute to $\beta$-cell failure and loss in the pathogenesis of T2DM.

\section{Supplementary data}

This is linked to the online version of the paper at http://dx.doi.org/10.1530/ JME-12-0105.
Declaration of interest

The authors declare that there is no conflict of interest that could be perceived as prejudicing the impartiality of the research reported.

\section{Funding}

This work was supported by a grant from Deutsche Diabetes Gesellschaft (DDG; Berlin, Germany) to H S and S S. H S was supported by a grant (STE 1782/2-2) from Deutsche Forschungsgemeinschaft (DFG; Bonn, Germany). H S is a Fellow of the National Foundation for Cancer Research (NFCR; Bethesda, MD, USA).

\section{Acknowledgements}

The authors thank A Borchardt, B Mülders-Opgenoorth, and D Schmiegelt for the excellent technical assistance.

\section{References}

Arteel GE, Mostert V, Oubrahim H, Briviba K, Abel J \& Sies H 1998 Protection by selenoprotein $\mathrm{P}$ in human plasma against peroxynitritemediated oxidation and nitration. Biological Chemistry 379 1201-1205.

Asfari M, Janjic D, Meda P, Li G, Halban PA \& Wollheim CB 1992 Establishment of 2-mercaptoethanol-dependent differentiated insulin-secreting cell lines. Endocrinology 130 167-178. (doi:10.1210/ en.130.1.167)

Bast A, Wolf G, Oberbäumer I \& Walther R 2002 Oxidative and nitrosative stress induces peroxiredoxins in pancreatic $\beta$ cells. Diabetologia $\mathbf{4 5}$ 867-876. (doi:10.1007/s00125-002-0846-1)

Bindokas VP, Kuznetsov A, Sreenan S, Polonsky KS, Roe MW \& Philipson LH 2003 Visualizing superoxide production in normal and diabetic rat islets of Langerhans. Journal of Biological Chemistry 278 9796-9801. (doi:10.1074/jbc.M206913200)

Burk RF \& Hill KE 2009 Selenoprotein P-expression, functions, and roles in mammals. Biochimica et Biophysica Acta 1790 1441-1447. (doi:10.1016/ j.bbagen.2009.03.026)

Campbell SC, Aldibbiat A, Marriott CE, Landy C, Ali T, Ferris WF, Butler CS, Shaw JA \& Macfarlane WM 2008 Selenium stimulates pancreatic $\beta$-cell gene expression and enhances islet function. FEBS Letters $\mathbf{5 8 2}$ 2333-2337. (doi:10.1016/j.febslet.2008.05.038)

Darville MI \& Eizirik DL 1998 Regulation by cytokines of the inducible nitric oxide synthase promoter in insulin-producing cells. Diabetologia 41 1101-1108. (doi:10.1007/s001250051036)

Donath MY, Størling J, Maedler K \& Mandrup-Poulsen T 2003 Inflammatory mediators and islet $\beta$-cell failure: a link between type 1 and type 2 diabetes. Journal of Molecular Medicine 81 455-470. (doi:10.1007/ s00109-003-0450-y)

Dreher I, Jakobs TC \& Köhrle J 1997 Cloning and characterization of the human selenoprotein P promoter. Response of selenoprotein P expression to cytokines in liver cells. Journal of Biological Chemistry 272 29364-29371. (doi:10.1074/jbc.272.46.29364)

Drews G, Krippeit-Drews P \& Düfer M 2010 Oxidative stress and $\beta$-cell dysfunction. Pflügers Archiv 460 703-718. (doi:10.1007/s00424-0100862-9)

Harmon JS, Bogdani M, Parazzoli SD, Mak SS, Oseid EA, Berghmans M, Leboeuf RC \& Robertson RP 2009 -Cell-specific overexpression of glutathione peroxidase preserves intranuclear MafA and reverses diabetes in db/db mice. Endocrinology 150 4855-4862. (doi:10.1210/ en.2009-0708)

Hoefig CS, Renko K, Köhrle J, Birringer M \& Schomburg L 2011 Comparison of different selenocompounds with respect to nutritional value vs.

Published by Bioscientifica Ltd. 
toxicity using liver cells in culture. Journal of Nutritional Biochemistry 22 945-955. (doi:10.1016/j.jnutbio.2010.08.006)

Hoffmann PR, Höge SC, Li PA, Hoffmann FW, Hashimoto AC \& Berry MJ 2007 The selenoproteome exhibits widely varying, tissue-specific dependence on selenoprotein P for selenium supply. Nucleic Acids Research 35 3963-3973. (doi:10.1093/nar/gkm355)

Hotamisligil GS, Shargill NS \& Spiegelman BM 1993 Adipose expression of tumor necrosis factor- $\alpha$ : direct role in obesity-linked insulin resistance. Science 259 87-91. (doi:10.1126/science.7678183)

Kahn SE 2003 The relative contributions of insulin resistance and $\beta$-cell dysfunction to the pathophysiology of type 2 diabetes. Diabetologia 46 3-19. (doi:10.1007/s00125-003-1190-9)

Kim JW \& Yoon KH 2011 Glucolipotoxicity in pancreatic $\beta$-cells. Diabetes \& Metabolism Journal 35 444-450. (doi:10.4093/dmj.2011.35.5.444)

Lakey JR, Suarez-Pinzon WL, Strynadka K, Korbutt GS, Rajotte RV, Mabley JG, Szabó C \& Rabinovitch A 2001 Peroxynitrite is a mediator of cytokine-induced destruction of human pancreatic islet $\beta$ cells Laboratory Investigation 81 1683-1692. (doi:10.1038/labinvest. 3780381)

Laybutt DR, Kaneto H, Hasenkamp W, Grey S, Jonas JC, Sgroi DC, Groff A, Ferran C, Bonner-Weir S, Sharma A et al. 2002 Increased expression of antioxidant and antiapoptotic genes in islets that may contribute to $\beta$-cell survival during chronic hyperglycemia. Diabetes 51 413-423. (doi:10.2337/diabetes.51.2.413)

Lee SR, Yon JM, Baek IJ, Kim MR, Park CG, Lee BJ, Yun YW \& Nam SY 2008 Spatiotemporal expression of the selenoprotein $P$ gene in postimplantational mouse embryos. International Journal of Developmental Biology 52 1005-1011. (doi:10.1387/ijdb.082656sl)

Lei XG \& Vatamaniuk MZ 2011 Two tales of antioxidant enzymes on $\beta$ cells and diabetes. Antioxidants \& Redox Signaling 14 489-503. (doi:10.1089/ ars.2010.3416)

Lenzen S 2008 The mechanisms of alloxan- and streptozotocin-induced diabetes. Diabetologia 51 216-226. (doi:10.1007/s00125-007-0886-7)

Lu WT, Juang JH, Hsu BR \& Huang HS 1998 Effects of high or low dose of streptozocin on pancreatic islets in C57BL/6 and C.B17-SCID mice. Transplantation Proceedings 30 609-610. (doi:10.1016/S00411345(97)01425-5)

Ma S, Hill KE, Caprioli RM \& Burk RF 2002 Mass spectrometric characterization of full-length rat selenoprotein $\mathrm{P}$ and three isoforms shortened at the $\mathrm{C}$ terminus. Evidence that three UGA codons in the mRNA open reading frame have alternative functions of specifying selenocysteine insertion or translation termination. Journal of Biological Chemistry 277 12749-12754. (doi:10.1074/jbc.M111462200)

Maechler P, Jornot L \& Wollheim CB 1999 Hydrogen peroxide alters mitochondrial activation and insulin secretion in pancreatic $\beta$ cells. Journal of Biological Chemistry 274 27905-27913. (doi:10.1074/jbc. 274. 39.27905)

McClung JP, Roneker CA, Mu W, Lisk DJ, Langlais P, Liu F \& Lei XG 2004 Development of insulin resistance and obesity in mice overexpressing cellular glutathione peroxidase. PNAS 101 8852-8857. (doi:10.1073/ pnas.0308096101)

Minn AH, Hafele C \& Shalev A 2005 Thioredoxin-interacting protein is stimulated by glucose through a carbohydrate response element and induces $\beta$-cell apoptosis. Endocrinology 146 2397-2405. (doi:10.1210/ en.2004-1378)

Misu H, Takamura T, Takayama H, Hayashi H, Matsuzawa-Nagata N, Kurita S, Ishikura K, Ando H, Takeshita Y, Ota T et al. 2010 A liverderived secretory protein, selenoprotein $\mathrm{P}$, causes insulin resistance. Cell Metabolism 12 483-495. (doi:10.1016/j.cmet.2010.09.015)

Morgan D, Oliveira-Emilio HR, Keane D, Hirata AE, Santos da Rocha M, Bordin S, Curi R, Newsholme P \& Carpinelli AR 2007 Glucose, palmitate and pro-inflammatory cytokines modulate production and activity of a phagocyte-like NADPH oxidase in rat pancreatic islets and a clonal $\beta$ cell line. Diabetologia 50 359-369. (doi:10.1007/s00125-006-0462-6)

Nishiyama A, Matsui M, Iwata S, Hirota K, Masutani H, Nakamura H, Takagi Y, Sono H, Gon Y \& Yodoi J 1999 Identification of thioredoxin-binding protein-2/vitamin $\mathrm{D}(3)$ up-regulated protein 1 as a negative regulator of thioredoxin function and expression. Journal of Biological Chemistry 274 21645-21650. (doi:10.1074/jbc.274.31.21645)

Niwa H, Harrison LC, DeAizpurua HJ \& Cram DS 1997 Identification of pancreatic $\beta$ cell-related genes by representational difference analysis. Endocrinology 138 1419-1426. (doi:10.1210/en.138.4.1419)

Nukatsuka M, Sakurai H, Yoshimura Y, Nishida M \& Kawada J 1988 Enhancement by streptozotocin of $\mathrm{O}_{2}$ - radical generation by the xanthine oxidase system of pancreatic $\beta$-cells. FEBS Letters 239 295-298. (doi:10.1016/0014-5793(88)80938-4)

Pi J, Bai Y, Zhang Q, Wong V, Floering LM, Daniel K, Reece JM, Deeney JT, Andersen ME, Corkey BE et al. 2007 Reactive oxygen species as a signal in glucose-stimulated insulin secretion. Diabetes 56 1783-1791. (doi:10.2337/db06-1601)

Poitout V \& Robertson RP 2008 Glucolipotoxicity: fuel excess and $\beta$-cell dysfunction. Endocrine Reviews 29 351-366. (doi:10.1210/er.2007-0023)

Schinner S, Scherbaum WA, Bornstein SR \& Barthel A 2005 Molecular mechanisms of insulin resistance. Diabetic Medicine 22 674-682. (doi:10.1111/j.1464-5491.2005.01566.x)

Schinner S, Ulgen F, Papewalis C, Schott M, Woelk A, Vidal-Puig A \& Scherbaum WA 2008 Regulation of insulin secretion, glucokinase gene transcription and $\beta$ cell proliferation by adipocyte-derived Wnt signalling molecules. Diabetologia 51 147-154. (doi:10.1007/ s00125-007-0848-0)

Sies H 1986 Biochemistry of oxidative stress. Angewandte Chemie International Edition in English 25 1058-1071. (doi:10.1002/anie. 198610581)

Speckmann B, Walter PL, Alili L, Reinehr R, Sies H, Klotz LO \& Steinbrenner H 2008 Selenoprotein P expression is controlled through interaction of the coactivator PGC- $1 \alpha$ with FoxO1a and hepatocyte nuclear factor $4 \alpha$ transcription factors. Hepatology $\mathbf{4 8}$ 1998-2006. (doi:10.1002/hep.22526)

Speckmann B, Sies H \& Steinbrenner H 2009 Attenuation of hepatic expression and secretion of selenoprotein $\mathrm{P}$ by metformin. Biochemical and Biophysical Research Communications 387 158-163. (doi:10.1016/ j.bbrc.2009.06.143)

Speckmann B, Pinto A, Winter M, Förster I, Sies H \& Steinbrenner H 2010 Proinflammatory cytokines down-regulate intestinal selenoprotein $\mathrm{P}$ biosynthesis via NOS2 induction. Free Radical Biology \& Medicine 49 777-785. (doi:10.1016/j.freeradbiomed.2010.05.035)

Steinbrenner H \& Sies H 2009 Protection against reactive oxygen species by selenoproteins. Biochimica et Biophysica Acta 1790 1478-1485. (doi:10.1016/j.bbagen.2009.02.014)

Steinbrenner H, Alili L, Bilgic E, Sies H \& Brenneisen P 2006 Involvement of selenoprotein $\mathrm{P}$ in protection of human astrocytes from oxidative damage. Free Radical Biology \& Medicine 40 1513-1523. (doi:10.1016/ j.freeradbiomed.2005.12.022)

Takebe G, Yarimizu J, Saito Y, Hayashi T, Nakamura H, Yodoi J, Nagasawa S \& Takahashi K 2002 A comparative study on the hydroperoxide and thiol specificity of the glutathione peroxidase family and selenoprotein P. Journal of Biological Chemistry 277 41254-41258. (doi:10.1074/jbc.M202773200)

Takeda Y, Fujita Y, Honjo J, Yanagimachi T, Sakagami H, Takiyama Y, Makino Y, Abiko A, Kieffer TJ \& Haneda M 2012 Reduction of both $\beta$ cell death and $\alpha$ cell proliferation by dipeptidyl peptidase- 4 inhibition in a streptozotocin-induced model of diabetes in mice. Diabetologia $\mathbf{5 5}$ 404-412. (doi:10.1007/s00125-011-2365-4)

Tang C, Han P, Oprescu AI, Lee SC, Gyulkhandanyan AV, Chan GN, Wheeler MB \& Giacca A 2007 Evidence for a role of superoxide generation in glucose-induced $\beta$-cell dysfunction in vivo. Diabetes 56 2722-2731. (doi:10.2337/db07-0279)

Tiedge M, Lortz S, Drinkgern J \& Lenzen S 1997 Relation between antioxidant enzyme gene expression and antioxidative defense status of insulin-producing cells. Diabetes 46 1733-1742. (doi:10.2337/ diabetes.46.11.1733) 
Turk J, Corbett JA, Ramanadham S, Bohrer A \& McDaniel ML 1993 Biochemical evidence for nitric oxide formation from streptozotocin in isolated pancreatic islets. Biochemical and Biophysical Research Communications 197 1458-1464. (doi:10.1006/bbrc.1993. 2641)

Twigger SN, Shimoyama M, Bromberg S, Kwitek AE, Jacob HJ \& RGD Team 2007 The Rat Genome Database, update 2007 - easing the path from disease to data and back again. Nucleic Acids Research 35 D658-D662. (doi:10.1093/nar/gkl988)

Wang XD, Vatamaniuk MZ, Wang SK, Roneker CA, Simmons RA \& Lei XG 2008 Molecular mechanisms for hyperinsulinaemia induced by overproduction of selenium-dependent glutathione peroxidase-1 in mice. Diabetologia 51 1515-1524. (doi:10.1007/ s00125-008-1055-3)
Weir GC \& Bonner-Weir S 2004 Five stages of evolving $\beta$-cell dysfunction during progression to diabetes. Diabetes 53 S16-S21. (doi:10.2337/ diabetes.53.suppl_3.S16)

Welsh M, Nielsen DA, MacKrell AJ \& Steiner DF 1985 Control of insulin gene expression in pancreatic $\beta$-cells and in an insulin-producing cell line, RIN-5F cells. II. Regulation of insulin mRNA stability. Journal of Biological Chemistry 260 13590-13594.

Zhang Y \& Chen X 2011 Reducing selenoprotein P expression suppresses adipocyte differentiation as a result of increased preadipocyte inflammation. American Journal of Physiology. Endocrinology and Metabolism 300 E77-E85. (doi:10.1152/ajpendo.00380.2010)

Zhang P, Liu C, Zhang C, Zhang Y, Shen P, Zhang J \& Zhang CY 2005 Free fatty acids increase PGC-1 $\alpha$ expression in isolated rat islets. FEBS Letters 579 1446-1452. (doi:10.1016/j.febslet.2005.01.046)

Received in final form 4 October 2012

Accepted 2 November 2012

Accepted Preprint published online 2 November 2012
Published by Bioscientifica Ltd. 